\title{
LA CITTÀ FELICE E OS GÊNEROS DO DISCURSO POLÍTICO NO RENASCIMENTO
}

\section{Helvio Gomes Moraes Junior ${ }^{*}$}

Resumo: Um dos primeiros escritos utópicos do Renascimento italiano, La città felice, do filósofo Francesco Patrizi da Cherso, traz as marcas da leitura de três textos paradigmáticos para o fundamento do pensamento político renascentista: A Política e a Ética a Nicômaco, de Aristóteles, e a República, de Platão. Neste estudo, abordamos a relação dialógica entre a utopia patriziana e tais textos (assim como a vasta literatura que deles se originou), acompanhando a história de sua recuperação na forma de traduções, comentários, elogios e tratados, com o objetivo de fornecer um quadro, conquanto não conclusivo, do universo textual que, no momento da escrita, apresentava-se a Patrizi.

Palavras-chave: Utopia. Filosofia Política. Renascimento.

Introdução

Dentre as várias utopias literárias que surgiram na Itália, a partir da segunda metade do século XVI, destacamos La città felice, um pequeno tratado escrito pelo filósofo Francesco Patrizi da Cherso, em 1551. Foi publicado em Veneza dois anos mais tarde, juntamente com outros escritos que remontam ao período em que o autor freqüentava o Studio paduano, como estudante de medicina, e traz marcas de suas primeiras leituras filosóficas - embora não devam ser vistos como meros exercícios acadêmicos, no sentido de uma disputatio. Tais escritos ainda nos chamam a atenção por já conterem os germes de temas bastante caros a Patrizi, que serão

* Professor da Universidade Estadual de Mato Grosso, campus de Pontes e Lacerda. Doutorando em Teoria e História Literária na Universidade Estadual de Campinas. No mestrado, estudou o pensamento utópico de Francesco Patrizi da Cherso e traduziu La città felice. No doutorado, prepara uma tradução comentada dos Dialoghi della historia, do mesmo autor. 
desenvolvidos posteriormente e constituirão o cerne de seu pensamento. Num sentido imediato, La città felice exprime suas convicções acerca do bom governo da cidade. É bastante provável que tenha pensado em concretizá-las, dedicando a obra a dois jovens Della Rovere $^{1}$, que, segundo o autor, haveriam de ser felizes e governar cidades e povos.

Trata-se, portanto, de uma utopia em moldes aristocráticos, em que se percebe uma rígida divisão de classes, evidenciada pela formação de dois grupos bastante distintos ${ }^{2}$. O primeiro, formado pelos escravos, artesãos e comerciantes, surge à medida que o autor reflete sobre os meios imediatos de satisfação das necessidades humanas - uma das premissas do projeto patriziano, que implica a inadmissão do excesso, ao restringir-se aos limites de uma vida frugal $^{3}$. Embora seja este o grupo que supre as exigências básicas de subsistência, o direito à cidadania lhe é vedado. Isso porque outra premissa que norteia o filósofo é a noção de felicidade, formulada por Aristóteles na Ética a Nicômaco, que, nas palavras de Patrizi, seria

1 Urbano Vigério e Girolamo della Rovere, dois colegas de Patrizi no Studio. Urbano Vigerio, já era bispo da Senigália, no momento em que a carta dedicaté é redigida. Girolamo (1528-1592) parece ter tido uma carreira mais coroada. Muito jovem, freqüentou as universidades de Pádua (onde, aos nove anos, disputò e perorò) e de Paris. Foi eleito bispo de Toulon, em 1560, e recebeu o cardinalato em 1586. Após sua morte, sua ampla biblioteca foi transportada para Urbino, que, na época, era governada pelos Della Rovere.

2 Para uma apreciação mais aprofundada da obra, remetemos à sua tradução em língua portuguesa: Moraes Jr (2004, p. 103-28). A versão original pode ser encontrada no site da Biblioteca Nacional da França: http://gallica.bnf.fr/Utopiel. Considerando o que propomos neste estudo, limitamo-nos a apresentá-la em suas linhas gerais.

3 Pode-se dizer que este princípio econômico encontra-se no traçado das principais cidades utópicas do Renascimento. Poderíamos aplicar, sem restrições, à utopia patriziana, aquilo que Logan e Adams (1999:XXXIV) dizem a respeito do método de Thomas Morus: "[...] a premissa do projeto é o princípio de autarkeia, auto-suficiência: a melhor república é aquela que engloba todo o necessário à felicidade de seus cidadãos, e nada além disso". A noção de autarquia já se encontra plenamente elaborada em Platão e Aristóteles, n' A República e n'A Política. 
"uma operação conforme a virtude perfeita, sem impedimento, em vida completa". Ainda que consigam chegar à velhice e satisfaçam suas necessidades mais elementares, escravos, artesãos e comerciantes encontram graves impecilhos ao exercício da vida contemplativa, dadas as agruras de suas ocupações diárias. A felicidade (e, por conseguinte, a cidadania) destina-se àqueles que se dedicam ao cultivo das virtudes morais e intelectivas. De onde, então, surge o segundo grupo, formado pelos magistrados, guerreiros e sacerdotes. Nesse ponto, é marcante a presença de Veneza, ou do mito que se forjara em torno da perfeição de sua constituição, que englobaria as melhores formas de governo postuladas por Platão e Aristóteles. O governante da Cidade Feliz, ao mesmo tempo em que personifica a noção do reifilósofo de Platão, claramente alude à imagem do doge veneziano. Semelhantes também são suas instituições públicas e a forma de ascensão ao poder, que, em ambos os casos, termina por configurar-se em uma gerontocracia.

Há na utopia um caráter fortemente naturalístico, obviamente tributário da recente formação médica de Patrizi, mas não menos do pensamento político aristotélico. De fato, ela é apresentada, na carta dedicatória, como uma síntese d'A Política, cujas idéias - expressas nos capítulos VI, VII e VIII do Livro II - são amplamente retomadas.

Contudo, é de se notar a presença de vários elementos platonizantes - marcada pela influência de Marsilio Ficino e da academia platônica de Florença -, para além dessa suposta síntese d'A Política. Tais elementos, sutilmente esparsos pela obra, já fornecem alguns indícios da afinidade do jovem Patrizi, desde suas primeiras leituras filosóficas, com os ambientes do neoplatonismo renascentista, em contraste com aquele que era, por excelência,

4 In Moraes Jr (2004, p.111). A primeira parte da definição engloba todas as virtudes intelectuais e morais, a segunda refere-se à conservação corporal (boa saúde, alimentação, conforto e disposição dos meios necessários para tê-los em abundância). Por fim, em relação à "vida completa", é dito que somente poderá ascender à felicidade aquele cujo "fio da vida" se estender por todo o curso da viver humano. 
reconhecido como o maior pólo da escolástica aristotélica italiana: o Studio paduano.

Temos, portanto, traçado, em linhas gerais, o pano de fundo sobre o qual surge a utopia patriziana. Nossa proposta, neste estudo, é justamente preencher um pouco mais esse quadro, investigando o lugar ocupado por La città felice dentro de um dado universo textual, o da literatura política renascentista, e a relação dialógica que estabelece com tais escritos.

La città felice e a tradição aristotélica

Numa época em que o diálogo se prolifera incontível, sobrepondo-se à tratadística que o precede (BENZONI, 1991, p. 23), a forma literária escolhida por Patrizi ainda se filia ao tratado de matriz aristotélica, cuja longa tradição havia atingido seu momento de maior vigor na Itália do Quattrocento. Não obstante a primazia da forma dialógica no século seguinte, o tratado em moldes aristotélicos ainda terá grande fortuna por quase dois séculos. Não só a Política, mas também a Ética a Nicômaco, inspiraram, por gerações, políticos e intelectuais, cujos interesses estavam grandemente vinculados à reflexão sobre a melhor forma de governo e, entre estes, um grupo que aspirava a "realizar, ou talvez mais a teorizar, novas repúblicas e novos estados" (CASTELLI, 2002, p. 3). Assim, temos uma vasta gama de escritos diretamente relacionados a esses textos, que se manifesta de diversos modos. Podemos destacar, primeiramente, suas traduções.

Já em meados do século XIII, surgem, pela primeira vez, as versões integrais de ambos os textos para o latim, feitas por Guilherme de Moerbeke. Até então, tais escritos eram pouco conhecidos, e, ainda assim, apenas de forma fragmentária ou através de comentários ${ }^{5}$.

5 Segundo Franceschini (1955, p.310-11), a história da recepção latina da Ética, anteriormente à tradução de Moerbeke, pode ser assim traçada: uma primeira versão parcial (livros II e III), diretamente do grego, surge em fins do século XII; não muito depois, foi acrescentada, a esta versão, a tradução do livro I (também do grego); em 1240, Hermannus Alemannus traduz do árabe o comentário de Averróis, e, por volta de 1243, publica uma versão parcial da Ética, que teve notáveis difusão e fortuna. 
Segundo Skinner (1996, p. 25-34; 70-74), a recuperação de tais obras, juntamente com sua influência nos escritos de eruditos do século XIV, como Bartolo de Saxoferrato e Marsílio de Pádua, é uma grande contribuição (muitas vezes despercebida) da escolástica para o êxito do discurso político, em defesa da liberdade das repúblicas italianas face à pretensão de domínio do Santo Império e, posteriormente, da Igreja romana. O pensamento moral e político aristotélico fornecia subsídios para a promoção do ideal de independência política e autogoverno das cidades-estado, os dois pilares sobre os quais se sustentava a noção de liberdade republicana que estes autores defendiam.

Contudo, maior fortuna que as traduções de Moerbeke teve a célebre tradução d'A Política, feita diretamente do grego por Leonardo Bruni, em 1438. Para fazermos uma idéia de sua influência no pensamento político do Renascimento, basta lembrar que, somente no século XVI, ela teve algo em torno de cinqüenta edições. A educação humanista de Bruni o faz criticar abertamente seus predecessores medievais, quanto à opacidade e à falta de elegância de suas traduções. Bruni já havia traduzido a Ética, em 1417, que também teve uma rápida e polêmica recepção ${ }^{6}$. Juntamente com seus outros escritos, tais traduções dão a Aristóteles o papel de destaque para o desenvolvimento daquilo que Baron define como "humanismo cívico florentino", ponto que talvez compartilhe apenas com Cícero.

Às vezes, as traduções dos humanistas são acompanhadas por comentários e reflexões pessoais, como é o caso de Donato Acciaiuoli que, segundo Garin, "está entre aqueles que não manifestam nenhum

6 Cf. Ezio Franceschini (1955, p. 300): “A tradução deve ter tido rápida fortuna, como indica o enorme número de manuscritos que chegaram até nós, e se já por volta de 1425 o filósofo e médico sienense Ugo Benzi a usava para as suas aulas públicas sobre o texto aristotélico. Mas as idéias expressas no prefácio com dureza de crítica em relação ao tradutor medieval, insólita pela força e pela violência, suscitaram ásperas reaçōes que perduraram, ainda mesmo após a morte de Bruni, por todo o século. E visto que Bruni reagiu, nasceu daí uma polêmica a respeito do modo de traduzir do grego, que a crítica recente tem amplamente, ainda que não completamente, ilustrado como um dos aspectos mais característicos e mais instrutivos da obra de Bruni e de seu tempo". 
hiato entre cultura e atividade civil" (apud CASTELLI, 2002, p. 6), sendo respeitado como grande intelectual, ao mesmo tempo em que desempenha a função de chanceler da república de Florença. Acciaiuoli traduz a Ética e a Política para Federico de Montefeltro, aspirando à realização de um novo estado fundado sobre a filosofia (CASTELLI, 2002, p. 6).

Além das traduções, prolifera uma longa série de elogios, e, como exemplo, podemos pensar novamente em Bruni, com sua Laudatio Florentine urbis, escrita anteriormente à tradução da Política. Um dos pontos mais influentes deste e de outros escritos de Bruni é o novo modo de ver a relação entre liberdade e poder (SKINNER, 1996, p. 101-2). O autor enfatiza que um dos méritos do regime republicano, observado principalmente em Florença, é que a ascensão às mais altas honras públicas pode ser almejada por todos os cidadãos. Essa igualdade de condições é fator decisivo para o crescimento e a conservação da república. Ela explicaria o aparecimento de tantos homens notáveis, pois uma vez que alguém, nesse estado de coisas, vislumbra a possibilidade de ascender ao poder, todos os seus talentos individuais são exercitados sem qualquer receio ou impedimento. Bruni, dessa forma, acirra o debate em torno da noção de nobreza, que terá grande fortuna desde então, a começar por seu contemporâneo, Poggio Bracciolini. Em 1440, Poggio escreve o diálogo De nobilitate, desafiando a noção tradicional de uma " nobreza adquirida pelo nascimento (KING, 1986, p. 118). A uma "nobreza de sangue", Poggio sobrepõe a "nobreza da alma", não mais hereditária, mas conquistada através do exercício das virtudes. Esse ponto de vista será rapidamente contestado em repúblicas de perfil aristocrático, como Veneza e Gênova. De fato, por volta de 1449, o nobre veneziano Lauro Quirini, escreve seu próprio De nobilitate, um tratado em resposta às idéias expostas por Poggio: enquanto este defende a noção de uma nobreza originada do cultivo das virtudes, aquele replica com a imagem da nobreza fundada na natureza: assim como há uma ordem hierárquica universal, em que todas as coisas derivam, em gradações, de uma primeira causa, superior a todas em nobreza e perfeição, o mesmo acontece com os homens, os animais e os elementos; e ainda que se considere cada espécie em particular, é possível verificar em cada uma delas diferentes graus de inteligência, nobreza e perfeição: "Aqueles, portanto, que, por natureza, excelem 
por certa sublimidade de alma e moderada e harmônica composição de corpo, chamamos nobres por natureza. [...] Estes são capazes de reger, governar e proteger tanto a República quanto a si mesmos"7. Quirini, conclui Margaret King (1986, p. 122),

não deixa esperança alguma [...] para a pessoa de origem comum. Nascida da turbulência e fetidez, seu futuro está selado. Assim como a forma corporal, os gestos e a voz dos pais são reproduzidos em suas crianças, da mesma forma o temperamento e o caráter são transmitidos pelo nascimento.

A polêmica intensifica-se nas décadas seguintes, e podemos observar que, até a publicação da obra central de Castiglione, ainda não há um consenso, visto que muitas páginas d'O Cortesão são dedicadas ao tema, e o diálogo entre Ludovico da Canossa e Gaspar Pallavicino encerra-se inconcluso.

Fazendo referência ao caráter algo concordista dessa primeira fase de Patrizi, observamos, pela forma de ingresso dos cidadãos nas instâncias do poder, que o filósofo prestigia um tipo de ascensão derivada dos esforços e habilidades individuais, embora delimite um campo onde possam ser encontrados esses requisitos para o governo da cidade: a classe aristocrática.

Outra série de elogios que têm por base os textos de Aristóteles, como os que Francesco Barbaro e Poggio Bracciolini compuseram, toma a organização política e social de Veneza como exemplo concreto e vivo dos postulados aristotélicos sobre as melhores formas de governo, culminando no que conhecemos por Mito de Veneza. Escrito em meados do Quattrocento, o De laude Venetiarum, de Poggio, ressalta a harmoniosa vida civil dos venezianos:

7 Apud King (1986, p. 121): "Those, therefore, who by nature excel by a certain loftiness of excellent soul and a temperate and harmonious composition of body, we call noble by nature. [...] They are able to rule, govern, and protect both themselves and the republic". Citaremos, em nota de rodapé, as passagens que traduzirmos de fontes primárias. Todas as traduções de citações em inglês são de minha autoria. 
Não há discórdia ou dissenso, entre os venezianos, quanto a como governar a república, nenhuma rixa entre cidadãos, nenhuma facção ou disputa, nem inimizades expostas. Todos eles mantêm a mesma opinião, todos eles com a mesma disposição apressam-se em socorro da república, para a qual dirigem seus constantes pensamentos e para cuja prosperidade despendem todos os seus esforços 8 .

Essa convivência pacífica tem uma única causa: "a combinação de monarquia e aristocracia dentro de uma mesma constituição" (BRACCIOLINI, 1997, p. 136). Como vemos, Poggio não menciona o elemento democrático da constituição veneziana, que, no entanto, está presente em outros escritos do período, como os de Pier Paolo Vergerio e Giorgio da Trebizonda. De fato, omite até mesmo a opinião positiva que Aristóteles sustenta em relação à democracia, ao fazer a seguinte afirmação: "Como Aristóteles diz, há vários tipos de constituição, dos quais dois em particular distinguemse do resto, a saber, a monarquia e a aristocracia, ou o que chamamos de governo dos melhores"?.

Por fim, a leitura de Aristóteles influencia uma intensa produção de tratados políticos. Para nos atermos apenas ao caso de Veneza, podemos citar nomes como os de Giovanni Caldiera, Lauro Quirini, Domenico Morosini e Pietro Barozzi, que se valem da autoridade de Aristóteles para enunciar, em tom conservador, a defesa dos ideais aristocráticos a que aspiram ${ }^{10}$. Já nos inícios do

8 Bracciollini (1997, p. 138): "There is no discord or dissent among the Venetians as to how to govern the republic, no feuding between citizens, no factions or quarrelling, no open enmities. All of them take the same view, all of them with one mind rush to the aid of the republic, to which they direct their constant thoughts and on whose welfare they spend all their effort".

9 Bracciollini (1997, p. 136): "As Aristotle says, there are various sorts of constitution, of which two in particular stand out from the rest, namely monarchy and aristocracy, or what we call the government by the best".

10 Esses tratados políticos, juntamente com as obras de Francesco Barbaro, Paolo Morosini e Ermolao Barbaro, produtos do peculiar humanismo 
Quattrocento, um frequientador do círculo humanista de Coluccio Salutati, Pier Paolo Vergerio, escreve um pequeno tratado, o De republica veneta, cujo ponto de partida é a exaltação da forma mista de governo veneziana:

A República Veneziana é regida por um governo composto pelos melhores homens, o tipo de regime que os gregos chamam de "aristocracia", que se mantém eqüidistante entre o regime monárquico e o democrático. Esta é superior porque participa dos bons aspectos de cada um desses extremos e concilia elementos de todo tipo de bom governo" ${ }^{11}$.

Como Poggio fará décadas depois, Vergerio também destaca o caráter primordialmente aristocrático da constituição veneziana, embora já faça alusão a seu elemento popular. Exclusivamente aristocrática é a forma de governo defendida por Lauro Quirini, em seu tratado De republica, escrito praticamente à mesma época do De nobilitate, visto acima. Enquanto neste o autor parte da metafísica aristotélica para a defesa de uma concepção de nobreza hereditária, originada na natureza, no De republica é a Política que vem a ser explicitamente evocada, desde o início, para a defesa de um governo aristocrático, em que a nobreza faz as escolhas mais apropriadas para garantir a liberdade da república e a felicidade dos cidadãos, cabendo ao povo apenas confirmar tais escolhas:

Pois as pessoas, em grande medida receosas umas das outras, ou igualmente irascíveis entre si, elegem os prudentes, que, com o melhor conselho administram a cidade. Por essa razão, estes poucos também fazem leis,

veneziano, são amplamente estudados por Margareth King (1986, p. 94161).

1 Vergerio (1997, p. 118): "The Venetian Republic is ruled by a government composed of the best men, the type of regime that the Greeks call an 'aristocracy', which takes a middle course between monarchical and democratic rule. It is superior because it partakes of the good aspects of each of these extremes and brings together elements from every type of good government". 
confirmadas pelo povo, executam a justiça e bem e prontamente guiam a república $^{12}$.

Em nenhum dos outros tratadistas, a defesa do regime aristocrático é feita de modo tão apaixonado como em Quirini, e esse é um elemento que, juntamente com sua declarada dívida para com o texto de Aristóteles, aproxima-o muito de Patrizi, estabelecendo um diálogo quase que pontual entre o De republica e La città felice.

Esse, portanto, é um pequeno elenco de obras que intensificam o debate político do Quattrocento, oriundo da emergência da Ética e da Política aristotélicas. Embora concernidos a formas textuais distintas, esses escritos eram lidos por toda a Itália, como nos mostra Castelli (2002, p. 7), com o fím específico de encontrar um modelo de governo racional. Conseqüentemente, os conceitos políticos neles presentes também

[...] revigoram aquela tratadística de arte que, a partir de Alberti, apresenta novos modelos de cidades, através de novas arquiteturas que simbolizam programas políticos. É difícil distinguir, em certo sentido, a tratadística de arte do Renascimento dos escritos políticos. De fato, mudando a cidade nos seus modelos legislativos, obrigatoriamente deve ser mudado, também, seu vulto ${ }^{13}$.[...] Seria longo, contudo, estender um elenco de textos que, a partir da metade do Quattrocento, abrem o caminho àquele gênero literário que concerne a utopia da

12 Apud King (1986, p. 126-7): For the people largely distrustful of each other or also quarrelsome among themselves elect those prudent ones who with the best advice administer the city. Hence these few also make laws, confirmed by the people, and execute justice and well and readily guide the republic.

13 Além de Alberti, Castelli (2002, p. 7) cita o projeto arquitetônico de Filarete, que "exalta, na celebração de sua Sforzinda, uma cidade mágica governada pelos céus, mas, todavia, guiada pela razão". Indicamos, igualmente, a importância de outro plano que se enquadra no gênero: uma série de desenhos de Leonardo da Vinci que compõem o Manuscrito B do Instituto de França, detalhadamente estudados por Garin (1990, p.137$54)$. 
cidade e que muitos têm colocado em referência à Città felice de Francesco Patrizi da Cherso [...]

De fato, considerando-se o aspecto formal do texto patriziano, percebemos que seu utopismo tem uma dívida bem maior com a tradição dos tratados políticos em moldes aristotélicos do que com a forma dialógica, característica das primeiras utopias, seja em moldes platônicos, de natureza didática, o que se dá nas utopias clássicas de Morus, Campanella e Bacon, seja por influência de Luciano, em composições de cunho burlesco, como a utopia de Anton Francesco Doni, Il mondo savio e pazzo.

Por conseqüência, a afirmação acima tenderia a sugerir, desde este ponto, uma compatibilidade entre os modelos de cidade perfeita de Patrizi e Aristóteles. No entanto, neste ponto, dissimula-se a intenção do filósofo de, sob a roupagem do pensamento peripatético, subvertê-lo com sutilezas e propor um plano de cidade vinculado, também, a outras correntes filosóficas, como o platonismo, o neoplatonismo de Ficino e o hermetismo.

\section{A influência d'A República de Platão}

Embora Patrizi não faça nenhuma referência explícita à República de Platão, em seu tratado, é possível perceber, em alguns trechos, a presença de certos elementos do pensamento político do filósofo grego. E, ainda que sejam poucas, as sugestões encontram-se em pontos bastante estratégicos, compondo um pano de fundo platônico em uma obra que, declaradamente, deveria ser uma síntese da Política aristotélica. Gostaríamos de aludir a duas delas: primeiramente, Patrizi só começa a idear sua cidade, seguindo mais pontualmente os capítulos finais do Livro II da Política, após mencionar que a busca da felicidade completa deve ter seu fim no "ser ideal", propondo, sutilmente, a imagem da contemplação filosófica como corolário da vida ativa. O outro ponto, que se tornara um topos na literatura política do Renascimento, é a grande proximidade da figura do governante da Cidade Feliz com a imagem do rei-filósofo de Platão.

É bastante provável que o contato do jovem autor com a República tenha se dado por meio da tradução de Ficino, publicada 
pela primeira vez em 1484, na primeira edição latina de todo o corpus platônico ${ }^{14}$. É verdade que por esse tempo outras traduções da obra já circulavam nos ambientes intelectuais do Vêneto.

A primeira tradução feita diretamente do grego surgiu nos inícios do Quattrocento, em Milão, por obra de Uberto Decembrio e seu mestre Manuel Chrysoloras, como forma de legitimar o governo principesco (ou signorile) de Giangaleazzo Visconti ${ }^{15}$. Embora asperamente criticada, a tradução teve uma certa fortuna e sabemos que pouco tempo depois ela já era conhecida dos intelectuais venezianos, conforme uma alusão que Pier Paolo Vergerio faz a Coluccio Salutati, numa carta escrita por volta de 1405, dizendo tê-la visto em Pádua, nas mãos de Carlo Zeno, um almirante veneziano (Cf. GARIN, 1955, p. 345).

Em torno de 1422, Decembrio termina seus diálogos $D e$ republica, fortemente inspirados no texto platônico. O autor deve têlos iniciado alguns anos após o retorno dos Visconti ao poder, com a ascensão de Filippo Maria, filho de Giangaleazzo, em 1412. Até

14 A crermos no testemunho que dá em sua carta autobiográfica, escrita a Baccio Valori, em 12 de janeiro de 1587 , em relação ao seu aprendizado do grego no primeiro ano de medicina, Patrizi poderia facilmente ter tido acesso ao texto na língua original, através da primeira edição do corpus platônico, feita por Aldo Manuzio, em 1514 (Cf. COPENHAVER, SCHMITT, 1992, p. 35).

J. Hankins (1994, p. 108-10) reforça a idéia de uma finalidade prática para o surgimento d'A República em Milão, quando afirma que "o aparecimento d'A República em latim, precisamente num momento em que teria tido considerável valor como propaganda, não foi inteiramente coincidente". Esse é justamente o momento $\mathrm{cm}$ que se acirra o conflito entre Milão e Florença pelo controle da parte central da Itália. A República poderia ser vista, portanto, como um texto modelar para a difusão do ideal dos signori, pois nela Platão descreve um estado onicompetente regido por reis-filósofos que são extraídos de uma casta militar especialmente educada. E conclui: "É fácil ver como a doutrina de Platão podia ser usada vantajosamente por um publicista milanês cujos lemas eram 'paz', 'estabilidade', 'ordem', c 'governo dos melhores', e como essas mesmas doutrinas podiam prover valiosa munição contra a alegação dos florentinos de estarem promovendo 'liberdade', 'autocontrole', 'espírito cívico', e a 'vantajosa competição de mentes livres'". 
então, Milão havia sido governada, na prática, pelo condottiere Facino Cane. Cane era extremamente hostil a Decembrio, a ponto de privá-lo da boa situação que gozava sob o regime dos Visconti, despojando-o de seus bens e enviando-o à prisão em 1410. Decembrio parece ter conquistado a simpatia do novo duque, pois, em 1419, consegue o posto de secretário ducal para o filho, Pier Candido, e, para si, o de podestà, em Treviglio, alguns anos depois. Isso pode explicar a renovada confiança do autor no governo principesco e seu ódio à tirania. Segundo Hankins,

seus apelos à autoridade de Platão eram [...] em grande medida retóricos. A República é uma fonte de autênticos textos comprobatórios que podem ser usados para fortalecer posições que Uberto já defende a priori [...]. [Uberto] faz uso seletivo das doutrinas políticas de Platão para analisar e justificar o conceito de regime senhorial. [...] identifica o regime senhorial com a constituição timocrática de Platão, e o regime republicano com a oligarquia de Platão. Uma vez que Platão julga a oligarquia como uma degeneração da timocracia, ele [Uberto] é capaz de mostrar que o regime senhorial é melhor e mais virtuoso que o governo de um regime republicano. Os horrores da constituição democrática e tirânica, ele ilustra por meio daquilo que é um relato profundamente vivenciado na recente história de Milão sob o tirano Facino Cane (1994, p. 113-4).

O caso de Decembrio pode ser visto como um exemplo bastante elucidativo da tese de Garin (1955, p. 347-8), segundo a qual "Propriamente o forte interesse prático que caracteriza grande parte da cultura quattrocentesca, e a necessidade de reconstruir de forma totalmente racional a "cidade", explica o desejo tão difuso [...] de ler em textos acessíveis uma obra como a de Platão".

Esse mesmo interesse prático pode ser observado na tradução da República feita por Pier Candido Decembrio, quase duas décadas após os diálogos do pai, sendo contemporânea da tradução da Política 
de Bruni ${ }^{16}$. Mais uma vez, a autoridade de Platão é usada na defesa do regime político milanês. Ao mesmo tempo, Pier Candido traça paralelos entre a sociedade de sua época e o mundo de Platão, como forma de indicar a relevância da obra para a reflexão sobre problemas contemporâneos ${ }^{17}$.

Entretanto, vários fatores, inexistentes à época de Chysoloras e Uberto, começaram a vir à tona, no lapso que separa os dois trabalhos, tornando mais complexo o contexto intelectual no qual se insere a atividade de Pier Candido como tradutor e intérprete do filósofo grego. Assim, vemo-lo passar grande parte dessa atividade ocupando-se em defender Platão das críticas de seus adversários ${ }^{18}$. No

16 De fato, Pier Candido Decembrio aproveita-se do fato de Bruni esquivarse de dedicar sua tradução ao duque Humphrey de Gloucester, o primeiro patrono inglês do humanismo (cf. SKINNER,1996, p. 214), para tentar seu patrocínio. Assim, a decisāo de traduzir a República pode ter sido ditada, também, por interesses de ordem pessoal. Pelo menos dois fatores interviriam para sua escolha do texto platônico: a necessidade de encontrar um texto tão importante quanto a Política e, dado seu restrito conhecimento da língua grega, a busca por textos que já haviam sido traduzidos (HANKINS,1944, p. 126). O início de sua polêmica com Bruni data de 1436, quando Decembrio compôs um Elogio à cidade de Milão, em moldes platônicos, em resposta ao que o florentino havia dedicado a Florença, no início do século.

"A guerra do virtuoso estado platônico contra seus ricos vizinhos é comparada à guerra de Milão contra Veneza, os sofistas são comparados aos pregadores contemporâneos e aos filósofos escolásticos, os gregos e bárbaros de Platão são identificados com italianos e europeus transalpinos, o pauperismo característico da constituição oligárquica é assimilado ao pauperismo em Milão. O texto da República se torna um bastão para açoitar os corruptos e perversos, especialmente o Papa, a cúria romana, os franceses, advogados e doutores, a nobreza, e os frades" (HANKINS, 1994, p. 134-5).

18 Após o surgimento da versão Uberto/Chrysoloras, ao mesmo tempo em que ocorre uma maior difusão do ensino do grego - e, conseqüientemente, um aumento no número de intelectuais habilitados a ler diretamente os textos originais -, sem nos esquecermos do renovado interesse do Quattrocento pelos textos platônicos, algumas passagens da República, dificilmente conciliáveis com a doutrina cristã, começam a ser mencionadas por aqueles 
que se refere à República, por exemplo, sendo a comunidade de bens e de mulheres a passagem mais problemática, a resposta de Pier Candido a seu adversário, Ugolino Pisano, é a seguinte: "Sócrates, de fato, não permite na República a posse comum de mulheres e bens; é que, meramente, o príncipe permite certa licença aos guardiães, sempre preservando uma decente ordem pública ${ }^{\prime \prime 19}$. Ao traduzir a passagem, torna-se claro que se cercara de cuidados, e o resultado é ambíguo: "[Deixe] as mulheres deste tipo serem possuídas

avessos ao platonismo, colocando obstáculos à aceitação de Platão no ocidente latino. Grande parte destes pontos polêmicos encontra-se no Livro V - justamente o primeiro a ser traduzido por Pier Candido, como contraposição às críticas de Aristóteles no Livro II da Política -, e está relacionada ao comunismo sexual e econômico. Tais críticas sempre existiram. No entanto, adquiriram maior vigor no Quattrocento, juntamente com novas acusações de imoralidade, por certas passagens de Platão que sugerem relações homossexuais, e de heresia, principalmente em referência à doutrina da transmigração das almas. Um destes críticos é Leonardo Bruni que, após uma primeira fase "platônica", parece ter-se rendido ao aristotelismo para a promoção do "humanismo cívico" em Florença, conservando uma atitude cheia de objeções aos postulados expressos na República, como podemos perceber nesta passagem de sua Vida de Aristóteles, escrita em 1429: "Ao estabelecer seu estado ideal, ele [Platão] expressou certas opiniões completamente repugnantes aos nossos costumes e modos de vida. Ele acreditava, por exemplo, que todas as mulheres deveriam ser mantidas em comum - dificilmente pode-se imaginar porque -, com o resultado de que ninguém seria capaz de distinguir seus próprios filhos daqueles de um perfeito estranho. Ele aboliria as leis de herança e possuiria todas as coisas em comum" (apud. HANKINS, 1994, p. 65). Ironicamente, Bruni havia feito planos, na juventude, de traduzir a República. Porém, quando a sugestão é feita, em 1441, pelo amigo Niccolò Ceva, as razōes para a recusa são claras: "Há muitas coisas naqueles livros [que são] repugnantes aos nossos costumes; coisas sobre as quais, para o próprio bem da honra de Platão, seria preferível permanecer em silêncio do que publicá-las" (Idem).

Apud Hankins (1994, p. 144): "Socrates does not in fact allow in the Republic the common ownership of women and goods; it is merely that the prince allows some license to the guardians, always preserving a decent public order". 
conjuntamente pelos guardiães, assim como as crianças, e não deixe nenhuma mulher viver separadamente deles"20.

Isso posto, percebemos que, aliada a um emprego nitidamente pragmático, a recuperação da obra platônica no Renascimento, em sua fase inicial, caracteriza-se pelo interesse em relação ao aspecto estritamente político de seu pensamento. É o que pode ser dito, também, de uma tradução de menor fortuna, embora superior à dos Decembri, como a de Antonio Cassarino, dedicada a Alfonso de Nápoles.

Logo após a metade do século, o pólo do platonismo quatrocentista transfere-se para a maior inimiga de Milão, Florença. Não surpreende, porém, que a mais famosa tradução da Replíblica surja num ambiente que, há poucas décadas, lhe era hostil ${ }^{21}$. As instituições públicas de Florença passaram por um rápido processo de transformação, quando, a partir de 1434, com o retorno de Cosimo de' Médici (il Vecchio) do exílio, verificou-se um movimento cada vez mais intenso para a instituição da Signoria. O humanismo cívico de Bruni, alicerçado nas autoridades de Aristóteles e Cícero, sofre frequientes golpes ${ }^{22}$, e o clima intelectual que se instaura mostra-se mais receptivo às idéias de Platão. Segundo Skinner (1996, p. 137),

20 Hankins (1994, p. 137): "[Let] women of this kind be possessed jointly by the guardian men, and children as well, and let no wife live separately from them".

21 Exemplo dessa animosidade é a polêmica em torno de um dos primeiros escritos de Ficino, as Institutione platonicae, de 1456, que foi visto como uma apologia de Platão. Albertini (2003, p. 107) acredita que a causa da reação dos florentinos tenha sido um clima intelectual ainda desfavorável ao platonismo, "razão pela qual o humanista Cristóforo Landino e outros apoiadores desrecomendaram a Ficino a publicação". Contudo, Cosimo de Medici, que igualmente havia tomado conhecimento do conteúdo das Institutiones, convenceu-se do talento filosófico de Marsílio e o encorajou a aprofundar seus estudos. Acreditamos também na hipótese de Cosimo ter percebido no pensamento platônico elementos que viriam legitimar seus interesses políticos e, por isso, passa a apoiar os estudos de Ficino. Não queremos dizer, com isso, que a defesa dos ideais republicanos chegue ao fim com a ascensão dos Medici. Uma nova onda de fervor republicano instaura-se, após a descida de Carlos VIII, em 1494, e, no século seguinte, a constituição republicana terá seu mais forte defensor em Maquiavel, com a publicação de seus Discorsi. 
"um efeito dessa mudança de devoção foi que o interesse voltado à política pelos humanistas do começo do século veio a ser tido como uma forma menor, e mesmo vulgar, de preocupação intelectual". O caminho está livre, portanto, para a superação da noção de negotium pelo ideal de vida contemplativa, tão bem materializado na figura de Marsílio Ficino. Não apenas seu desinteresse pela vida pública, evidenciado nos longos anos de refúgio na villa que recebera como presente de Cosimo, mas a própria maneira como interpreta e difunde o corpus platônico são característicos dessa nova atitude. Podemos, então, concluir que, enquanto as traduções dos Decembri respiram um forte elemento de propaganda, visando persuadir o maior público possível da validade e excelência da forma de governo de Milão, a de Ficino surge motivada por diferentes aspirações intelectuais (mais contidas no âmbito da religião), e destinada a um público mais limitado. Ela serviria como exemplo de outro efeito da "mudança de devoção" a que Skinner (1996, p. 137) faz menção:

[...] os primeiros humanistas "cívicos" supunham como normal um contexto em que as instituições fossem republicanas, e costumavam dirigir seus conselhos e exortações ao corpo inteiro de seus concidadãos. [...] quando chegamos aos humanistas da Renascença tardia, quase sempre vemos que pressupõem um contexto no qual o governo cabe a príncipes [...]. Notamos, por conseguinte, que eles tendem a minimizar a importância do cidadão individualmente considerado, e a centrar toda a sua atenção na figura muito mais imponente e influente do príncipe.

Em várias passagens de seus escritos, Ficino alude à sua atividade de tradutor e intérprete de Platão como obra da Providência, e às imagens de Cosimo, Piero e Lorenzo de' Medici como patronos desse magnífico retorno do platonismo, único remédio capaz de curar as mazelas da sociedade contemporânea. Tais imagens são facilmente condutíveis à noção do rei-filósofo, por sua síntese de erudição e prudência na manutenção do bem público. O retrato que traça de Cosimo é o de um grande líder que recorre, em qualquer eventualidade, pública ou privada, aos ensinamentos de um Platão que fala por intermédio de seu protégé. A República, por exemplo, é colocada em evidência - no comentário ao Parmênides -, como o 
compêndio completo da doutrina moral platônica (Cf. HANKINS, 1994, p. 335). Esse elemento formador da personalidade do futuro governante é elucidado no comentário à República:

[Platão] educa o filósofo e o cidadão usando um plano completamente similar, e isto com bom motivo.Pois ele declara no Político e no Sofista que o homem civil [...] e o filósofo são o mesmo. Prova que nele haveria de coincidir dois gêneros que muito raramente coincidem nos homens: uma natureza,[...] que é inteligente, condizente à contemplação, ardente de desejo pela verdade, e uma natureza que é autoritária, vigorosamente ativa, e providente com respeito ao bem comum.Uma inteligência deste tipo, ele conduz por todos os graus do saber, como é evidente no Livro Sete. Ele ordena que lhe seja dada prática na ciência de governar, e o põe à prova desveladamente, como o ouro pelo fogo, em meio a prazeres, dores, trabalhos e perigos, antes de confiar-lhe o governo da cidade. No entanto, a primeira necessidade julga ser o conhecimento do Bem em Si, o mais notável de todos os conhecimentos ${ }^{23}$.

Noutro pequeno trecho de seu comentário ao Livro VII, Ficino enfatiza a idéia contida no final da citação acima: "Após o

23 Apud Hankins (1994, p. 294-5): "[Plato] educates the philosopher and the citizen using a completely similar plan, and this with good cause. For he lays it down in the Statesman and Sophist that the civil or royal man and the philosopher are one and the same. He proves that there ought to coincide in him two genera which very rarely do coincide in men: a nature, that is, which is sharp-witted, suited to contemplation, burning with desire for truth, and a nature which is authoritative, strenuously active, and provident with respect to the common good. An intelligence of this sort he leads up through all the grades of learning, as is clear in Book Seven. He commands that he be given practice in statesmanship, and tests and proves him carefully, like gold by fire, in the midst of pleasures, pains, labors, and dangers, before he entrusts the governance of the city to him. Yet the primary necessity he judges to be his knowledge of the Good Itself, the most outstanding of all knowledges". 
Filósofo ter contemplado Deus e seu governo celestial, somente então, e somente ele, poderá governar as coisas terrenas num modo divino"24.

Nos últimos capítulos de sua utopia, Patrizi delineia um projeto pedagógico que acolhe esses pontos avançados por Ficino. Ele mesmo se vê capaz de planear sua cidade somente após haver contemplado a infinita bondade de Deus. Como vimos, para efetivá-la, dedica sua obra aos jovens Della Rovere, "que hão de ser felizes e hão de governar cidades e povos" (MORAES JR, 2004, p. 109), buscando tornar-se uma espécie de conselheiro que muito se assemelha à pessoa de Ficino.

Todas essas similitudes são ainda reforçadas pelas referências que ambos fazem a termos médicos. Não são meras alusões, visto que ocupam posições centrais de suas obras. Ficino (assim como Patrizi, um século depois) recebera formação médica na juventude, seguindo os passos do pai famoso. Refere-se aos problemas de sua época como doenças que afetam o corpo político de Florença. Adolescente, testemunhou as disputas facciosas entre os republicanos e os que apoiavam a forma oligárquica, encabeçada pelos Medici. Demonstrava, também, certo enfado pela cultura humanista de seus predecessores, que relegava a teologia a uma posição marginal em seus escritos, promovendo, portanto, uma cisão entre religião e filosofia, causadora de todos os distúrbios sociais. A cura de tais enfermidades estaria nos escritos do "divino Platão", que equilibravam perfeitamente política e religião, e seria ministrada por ele próprio, que, além de médico dos corpos, tornar-se-ia também médico das almas ${ }^{25}$.

24 Ibid.: "After the Philosopher has contemplated God and his celestial government, then only, and only he, can govern earthly things in a divine manner".

25 "Eu, o menor dos sacerdotes, tive dois pais, Ficino, o médico, e Cosimo de' Medici. De um, nasci; do outro, renasci.O primeiro recomendou-me a Galeno (doutor e seguidor do platonismo); o outro me consagrou ao divino Platão. Ambos aquele e este destinaram-me a ser doutor, um Galeno, médico dos corpos, assim como um Platão, médico das almas. Já por algum tempo, tenho, portanto, praticado medicina salutar sob Platão" (apud HANKINS, 1994, p. 291). 
Mencionamos anteriormente que La città felice ressente dos estudos médicos recém-concluídos de seu autor. Na verdade, Patrizi parte de conceitos médicos para a elaboração de sua cidade ideal, preocupado com a saúde corporal de seus cidadãos e a do corpo social, livre de dissensões civis, como estágios obrigatórios que permitem a tais cidadãos "doar todo o ânimo às virtudes civis e contemplativas, banhando-se nas águas salutares do feliz regato" (In MORAES JR, 2004, p. 120-126).

\section{Conclusão}

Os pontos que levantamos nos autorizam a afirmar que Patrizi, ao escrever La città felice, olhava para o neoplatonismo de Ficino, que se apresentava no horizonte, enquanto trazia nas mãos o tratado aristotélico. Afinal, Patrizi construiria sua obra naquele desvão onde o platonismo e o aristotelismo são falsamente dicotômicos. Essa relação de dependência e de conciliação entre os dois sistemas (juntamente com alguns laivos de noções herméticas, não incomum na filosofia renascentista - Giovanni Pico é também uma referência importante para Patrizi) passará por grandes transformações, durante a vida do filósofo, a ponto de uma historiografia literária que chega até décadas recentes, e que remonta às severas críticas de Giordano Bruno $^{26}$, reconhecê-lo (ou, talvez fosse melhor dizer, recriminá-lo) como ferrenho contestador da filosofia aristotélica. De qualquer forma, La città felice pertence à fase concordista do jovem filósofo, quando, ainda imerso no ambiente do Studio, estruturava $\mathrm{o}$ arcabouço de todo o seu pensamento.

Em La città felice, a carga de utopismo $a b$ ovo contida num texto como a República impregna o conteúdo do tratattello e faz com que o estudo de Patrizi não seja redutível somente a uma análise da realidade política - elogio, comentário ou propaganda de dado sistema de governo -, mas a uma projeção, no tempo, dessa realidade, na idealização de um momento em que suas contradições são resolvidas.

${ }^{26}$ Cf. S. Plastina (1992, p. 7-8), quando se refere às críticas de Bruno às Discussiones peripateticae de Patrizi. 


\section{Referências}

ALBERTINI, Tamara. Marsilio Ficino (1433-1499). Dar forma estética ao mundo por meio do pensamento. Trad. Nélio Schneider. In: BLUM, Paul Richard (org.). Filósofos da Renascença. São Leopoldo: Unisinos, 2003.

BENZONI, Gino. La forma dialogo: un'apertura con chiusura. In: BRANCA, Vittore; OSSOLA, Carlo (ed.). Crisi e rinovamenti nell'autunno del Rinascimento a Venezia. Firenze: Leo S. Olschki Editore, 1991.

BRACCIOLINI, Poggio. In Praise of the Venetian Republic. Trad. Martin Davies. In: KRAYE, Jill (ed.). Cambridge Translations of Renaissance Philosophical Texts. Vol. 2: Political Philosophy. Cambridge: Cambridge University Press, 1997.

CASTELLI, Patrizia. Le fonti de La Città Felice. In: CASTELLI, P. (ed.). Francesco Patrizi filosofo platonico nel crepuscolo del Rinascimento. Firenze: Leo Olschki Editore, 2002.

CASTIGLIONE, BALDASSARE. Il libro del cortegiano. In: MAIER, Bruno (ed.). Il libro del Cortigiano con una scelta delle Opere minori. Torino: Unione Tipografico-Editrice Torinese, 1981.

COPENHAVER, Brian P. \& SCHMITT, Charles B. Renaissance Philosophy. Oxford: Oxford University Press, 1992.

FRANCESCHINI, Ezio. Leonardo Bruni e il Vetus Interpres dell'Etica a Nicomaco. In: VVAA. Medioevo e Rinascimento. Firenze: G. C. Sansoni, 1955.

HANKINS, James. Plato in the Italian Renaissance. Leiden: E. J. Brill, 1994.

GARIN, Eugenio. Rinascite e Rivoluzioni. Roma: Laterza, 1990.

GARIN, Eugenio. Richerche sulle traduzioni di Platone nella prima metà del sec. XV. In: VVAA. Medioevo e Rinascimento. Firenze: G. C. Sansoni, 1955.

KING, Margaret L. Venetian Humanism in an Age of Patrician Dominance. Princeton: Princeton University Press, 1986. 
LOGAN, George M.; ADAMS, Robert M. Introdução. In: MORE, Thomas. Utopia. Trad. Jefferson Luiz Camargo e Marcelo Brandão Cipolla. São Paulo: Martins Fontes, 1999.

MORAES JR., Helvio Gomes. A Cidade Feliz: a Utopia Aristocrática de Francesco Patrizi. Morus - Utopia e Renascimento. Campinas, n. 1, 2004, p. 103-28.

PLASTINA, Sandra. Gli alunni di Crono - Mito linguaggio e storia in Francesco Patrizi da Cherso (1529-1597). Messina: Rubbettino Editore, 1992.

SKINNER, Quentin. As Fundações do Pensamento Político Moderno. Trad. Renato Janine Ribeiro e Laura Teixeira Motta. São Paulo: Cia. das Letras, 1996.

VERGERIO, Pier Paolo. The Venetian Republic: Selections. Trad. Ronald G. Witt. In: KRAYE, Jill (ed.). Cambridge Translations of Renaissance Philosophical Texts. Vol. 2: Political Philosophy. Cambridge: Cambridge University Press, 1997. 